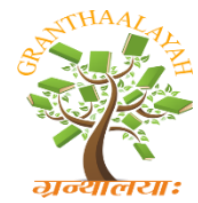

INTERNATIONAL JOURNAL OF RESEARCH GRANTHAALAYAH A knowledge Repository

Science

\title{
COMPARATIVE STUDY OF COMPLETED SUICIDE BASED ON SEASON AND DISEASES IN BUSHEHR PROVINCE, (2006-2015)
}

\author{
Mahmood Montazeri ${ }^{1}$, Hiyam Hosseini ${ }^{* 2}$, Behroz Jokar ${ }^{3}$ \\ ${ }^{1}$ Public Dr., Forensic Medicine, Legal Medicine Center of Bushehr, Bushehr, Iran \\ ${ }^{* 2}$ MS Toxicology, Forensic Medicine, Legal Medicine Center of Bushehr, Bushehr, Iran \\ ${ }^{3}$ MS of Law, Forensic Medicine, Legal Medicine Center of Bushehr, Bushehr, Iran
}

DOI: https://doi.org/10.29121/granthaalayah.v5.i4.2017.1822

\begin{abstract}
Suicide, an act in which individuals sacrifice voluntarily themselves, is considered as a serious psychosocial problem. The main objective of the present study was to determine the comparative study of completed suicide based on season and diseases in Bushehr during 2006-2015. This consideration has been done as a retrospective cross-sectional study; the data were collected by the check list. After coordination to the medico legal 343 cases of completed suicide lead to death over a ten year period from 2006 to 2015 were extracted and the data were analyses by SPSS software. Completed suicides were most prevalent in spring $29.7 \%$ (102), whereas least prevalent in autumn $20.1 \%$ (69). There was no significantly in different seasons in year $(\mathrm{P}=0.065)$. But, was a statistically significant difference observed in the different gender and different seasons of the year $(\mathrm{P}=0.001)$. The maximum number of completed suicides $10.2 \%$ (35) was observed in April, while the minimum number 6.1\% (21) was reported in September and October, too. The value Chi square test was statistically significant differences diseases and different seasons $(\mathrm{P}=0.001)$. The psychological disease was observed most in spring and winter seasons. Also was a significant relationship between season of the year and the method of suicide $(\mathrm{P}=0.001)$. The number of completed suicides was higher in moderate and cold seasons.
\end{abstract}

Keywords: Completed Suicide; Seasonality; Diseases; Bushehr.

Cite This Article: Mahmood Montazeri, Hiyam Hosseini, and Behroz Jokar. (2017). "COMPARATIVE STUDY OF COMPLETED SUICIDE BASED ON SEASON AND DISEASES IN BUSHEHR PROVINCE, (2006-2015)." International Journal of Research Granthaalayah, 5(4), 285-291. https://doi.org/10.29121/granthaalayah.v5.i4.2017.1822.

\section{Introduction}

Suicide, a social and mental phenomenon, is a major health problem in most countries so was the second leading cause for individuals between the ages of 15-20 years $(1,2)$. Yet data relating to the role social factors play in the development of this condition are lacking within low- and 
middle-income countries. The official statistics of the World Health Organization (WHO), reported the rate of suicide (per 100,000 people) ranged from 0.6 to 35.1 (3). In Iran, statistics show a number of 5.7 and 3.1 suicides per 100,000 people in men and women in 2001, respectively (4). Countries with high rates of older adult suicide has included European Union countries, Canada, the U.S., and several Asian countries, including Japan, Singapore, and Taiwan The rate of suicide in Iran is lower than western countries but is in a higher level in Middle East countries $(4,5)$. Therefore, the explanation of the suicide phenomenon and the identification of the universally valid causes thereof are far from being final and it is generally accepted that the reasons for the suicidal behavior has variations from society to society, from women to men, from a season to another(6) On top of the abovementioned risk factors of suicide, i.e. age, gender, diseases etc., seasonality is also believed to be a major factor influencing the rate of suicide, which was first reported by Morselli (8). He observed that the rate of suicide peaked in summer. He also believed that this peak co-occurred with the summer pick observed for mental disorders. More recent studies on the seasonality of suicide have shown contradictory results(7) The most common method of suicide in in many Asian countries, fifteen European countries, in many Western countries is suicide by hanging (8-10) and in developed countries are firearms, car exhaust and poisoning, whereas in developing countries, they are pesticide poisoning, hanging and self-immolation (11). In the United States, the most common method of suicide was firearm (12). The most common methods of suicide among people who live in Iran were hanging, Selfimmolation, firearms and poisoning (13) The main objective of the present study was to explore comparative study of completed suicide based on season and diseases in Bushehr Province during 2006 and 2015(14). These factors may vary significantly for different countries due to distinctions within social and cultural constructs (15) which need to be considered in suicide prevention planning (16).

\section{Materials and Methods}

This Ten-year population-based survey was conducted in Bushehr Province, the South of Iran, in 2015. The data on completed suicide was collected for ten successive years from 21 March 2006 to 20 March 2015 suicide, the data were compared with and adapted by information on suicide recoded by the Center of Province Forensic Medicine. In analytical and cross sectional study pre conducted forms of suicide was engaged to register data, crude and specific completed suicides rates was computed along with other demographic variables such as age, gender, season and month related to completed suicide and suicide method. After collecting and coding the data, they were entered into SPSS software (version 19, SPSS Inc., Chicago, IL, USA) for analysis and calculation of the frequency of the most common methods of suicide in Bushehr province. Chi- square test was performed to compare 2the frequencies in different categories. Analysis of variance (ANOVA) was also used to compare means in different groups or seasons. Finally, to comply In order to maintain confidentiality, the individual's name, address, and phone number were not used. P-values lower than 0.05 were considered significant.

\section{Results}

A total number of 343 completed suicides where recorded over the entire study period (20062015) in Bushehr Province. Fig 1 illustrates the frequency of completed suicides over 2006-2015 in different seasons of the years. Fig 2 depicts the frequency of completed suicides over 2006- 
2015 in different months of the year. There is statistically significant difference was observed in different months and different gender $(p=0.0001)$ Fig 3 . Of the total cases of completed suicide, $68.5 \%$ were men while $31.5 \%$ were women. Furthermore, the frequency of completed suicides in different gender was higher in spring (30.0\%) than in other seasons $(25.7 \%$ in winter, $24.5 \%$ in summer, and $19.8 \%$ in autumn $)(P=0.065)$. Mean $(\mathrm{SD})$ age of individuals having committed suicide was 28.7 years. This value did not change significantly in different seasons $(P=0.941)$. But, statistically significant difference was observed in the method of suicide across different seasons of the year $(P=0.0001)$. The relative of different methods used for suicide in different seasons of the year is presented in Fig 4. The frequency of psychological diseases and physical diseases of completed suicide cases in different season of years Fig $5(P=0.0001)$.

\section{Discussion}

Recent studies have challenged the traditional idea that seasonal effects on suicide are a unitary phenomenon, not influenced by age, gender, or circumstances of the act. The seasonal occurrence of suicides has been found to differ significantly between the young and the elderly, and differences have also been found between male and female cycles of occurrence. Suicides using violent methods follow clearer seasonal patterns than those using less violent methods, such as drug or gas poisoning, reflecting the greater impulsive component involved in the choice of a violent lethal means. It is concluded that climate affects suicide rate by modifying the responsiveness of the circuits that control mood and behavior and acting on the frequency and intensity of social intercourse. This research aims to test the actuality of the current specialty literature affirmations, which maintain that suicide based on the criterion of season is ranked as follows: summer, spring, autumn and winter. The highest number of completed suicides recorded by the present study occurred in moderate season (March to May), while the lowest number was observed in cold season (September to November). Based on gender, the comparative analysis showed, for each season, that the differences are kept between the genders at a statistically significant level, which allows us to take into account for future use a qualitative analysis which could emphasize the differences between genders regarding the decision to use such behavior. The methods and means used by the two genders are relatively different, as men use more hanging and lethal weapons than females and females have a higher rate of self-immolation than the men in spring season. The psychological disease was observed most in winter season for men and spring season for female. The study in South Korea and found increased number of completed suicides in summer and spring(17), compared to those found in spring and winter.

Another study which evaluated the effect of month on suicidal behavior in Western Australia reported a notable spring peak of deliberate Self harm and a significantly increased in spring within the deliberate self-harm group(18). Swiss suicide data depict the expected pattern with a peak in May and June and a low in December. The decrease of the frequencies culminates at Christmas/New Year and then returns to average levels. Hence, the seasonality of the overall Swiss suicide frequencies is but a compound seasonality(19). Recent research has shown that in Western countries the seasonality of suicide is tending to diminish and may, eventually, disappear. It can no longer be considered a universal and homogeneous phenomenon. In addition, different major seasonal cycles have now been determined which mainly depend on different suicide methods. Just as in the epidemiology of suicide methods, the (seasonal) availability and perceived adequacy of methods emerge as the major driving force beyond the seasonal phenomena in suicide(19). Previous 
studies have found that rates of suicide have a distinct annual rhythm with a peak in spring. Two recent European studies, however, have found that the amplitude of this rhythm has decreased over time. The seasonal amplitude has increased over time. Males who use violent methods determine the seasonal effect. These results support previous findings that suicide and particularly violent suicide have a characteristic seasonal rhythm. However, the progressive increase in the amplitude of this rhythm over time in Australia is in direct contrast to other European finding(20). The seasonal pattern for attempted suicide was similar with that seen for suicide with a spring peak and a nadir in December, but only in females(7).

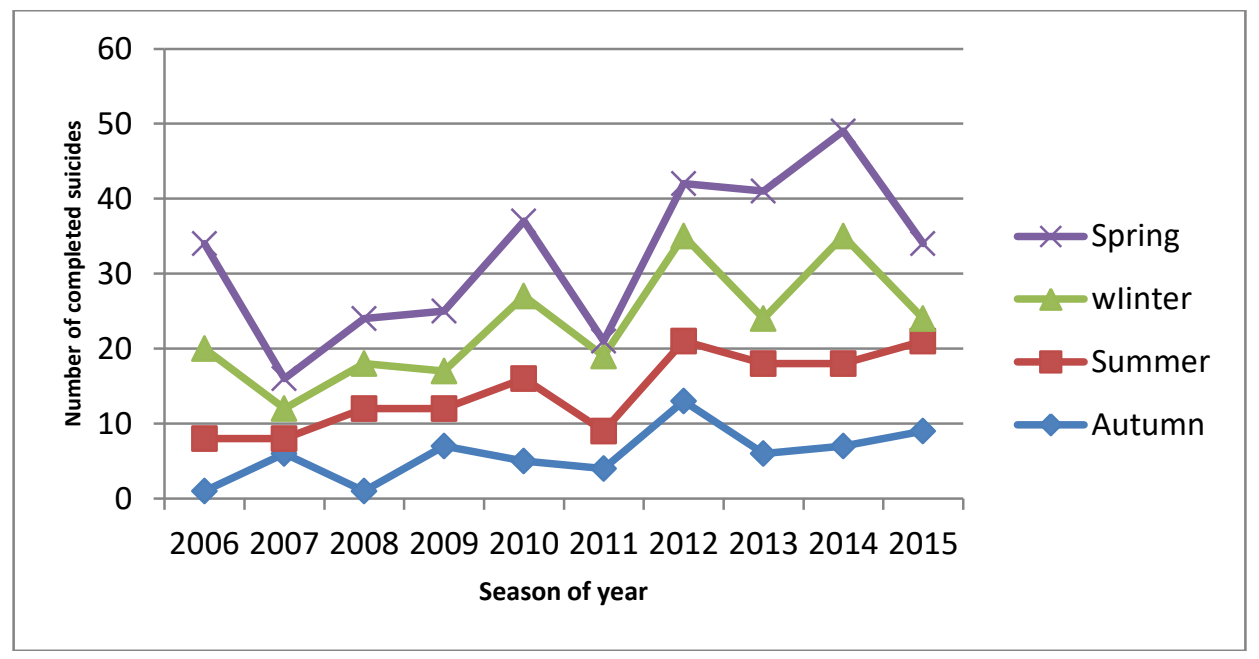

Figure 1: The frequency of completed suicides over 2006-2015 in different seasons of the years

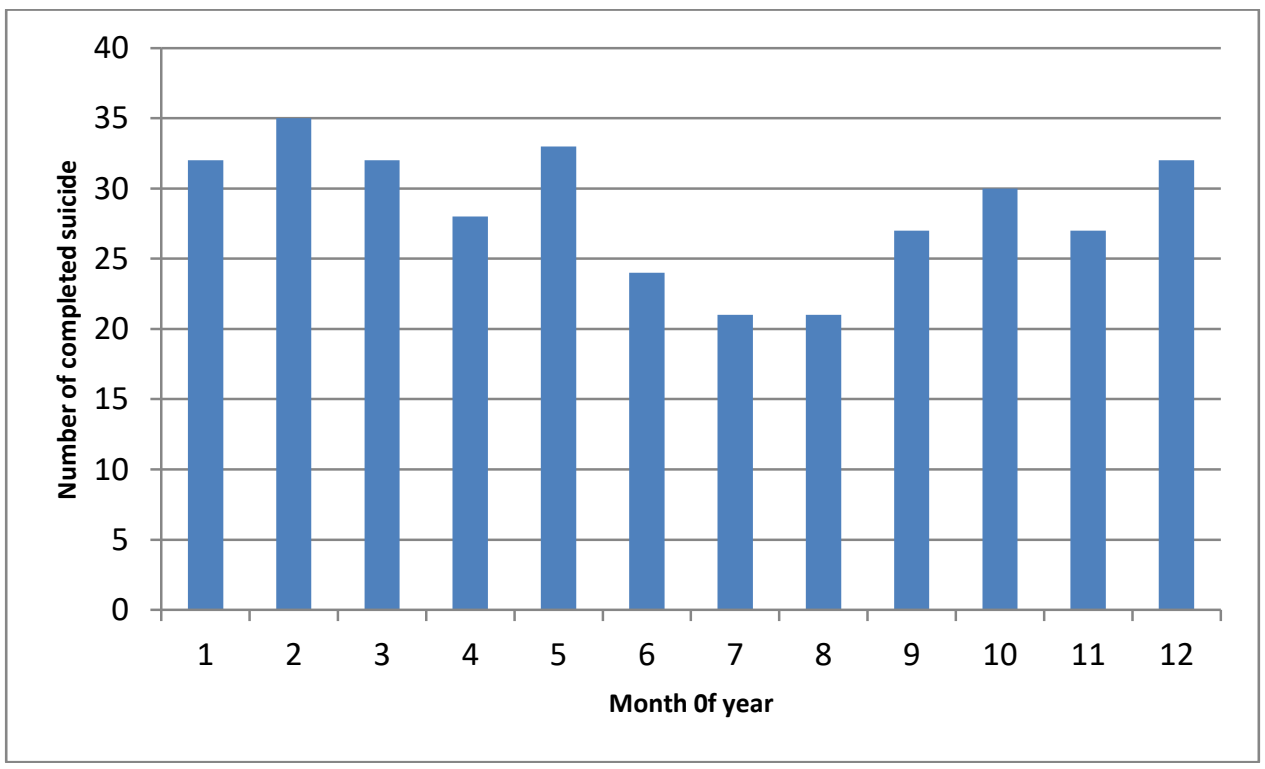

Figure 2: The frequency of completed suicides over 2006-2015 in different months 


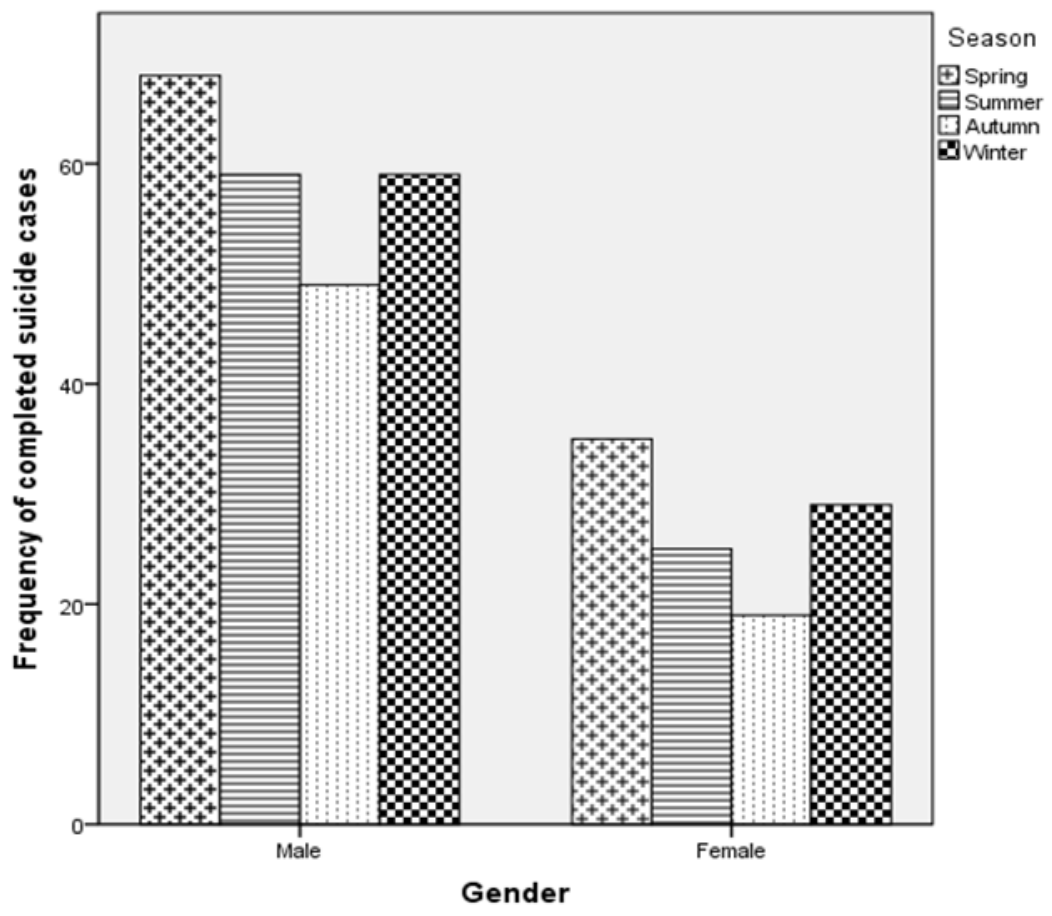

Figure 3: The frequency of different season of years based on gender

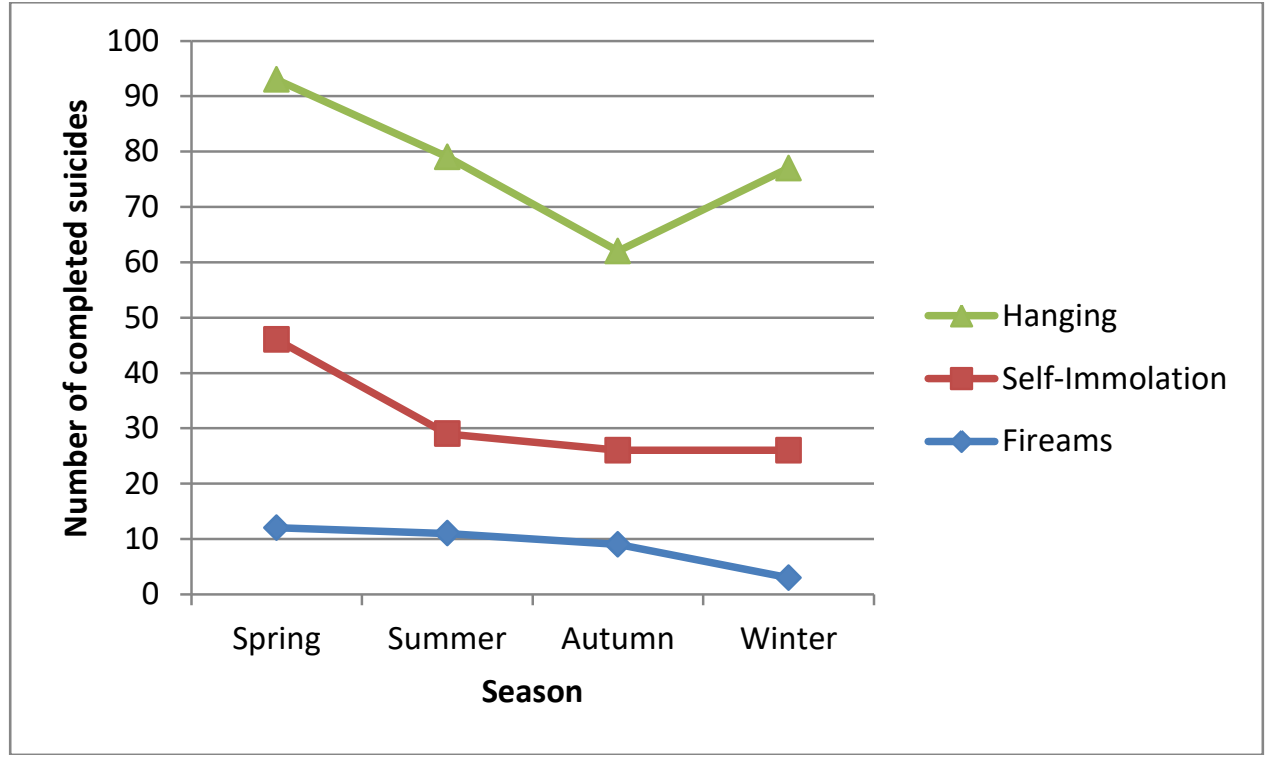

Figure 4: The relative frequency of different methods of completed suicide in different seasons of the year 


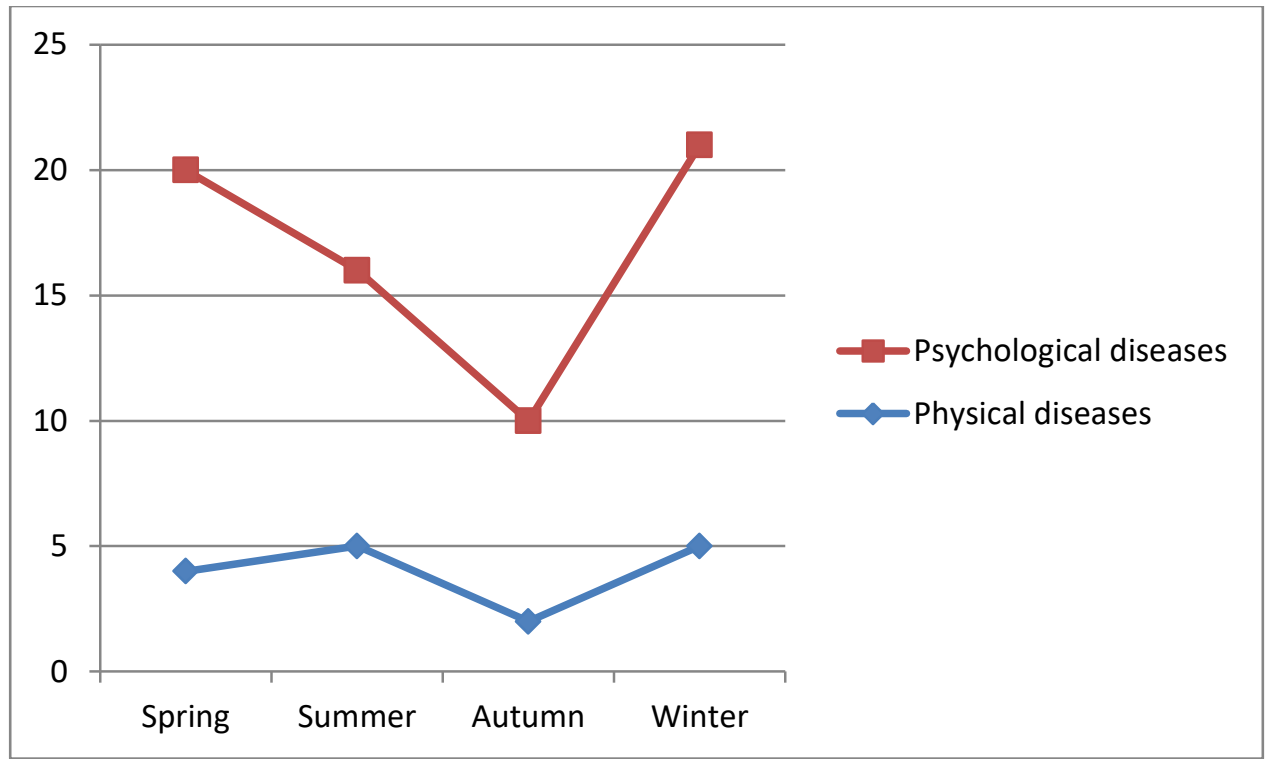

Figure 5: The frequency of diseases of completed suicide in different season of years

\section{Acknowledgement}

The authors wish to thank the Legal Medicine Center of Bushehr Province for providing us with the financial support to conduct this study. The authors declare that there is no conflict of interest.

\section{References}

[1] Evans E, Hawton K, Rodham K. Factors associated with suicidal phenomena in adolescents: a systematic review of population-based studies. Clin Psychol Rev. 2004 Dec;24(8):957-79. PubMed PMID: 15533280. Epub 2004/11/10. Eng.

[2] Conwell Y, Van Orden K, Caine ED. Suicide in older adults. Psychiatric Clinics of North America. 2011;34(2):451-68.

[3] Malakouti SK, Davoudi F, Khalid S, Asl MA, Khan MM, Alirezaei N, et al. The Epidemiology of Suicide Behaviors among the Countries of the Eastern Mediterranean Region of WHO: a Systematic Review. Acta Medica Iranica. 2015;53(5):257-65.

[4] MORADI SE. Evaluation of suicides resulting in death in Iran, comparing with the world rates. 2002.

[5] Eskandarieh S, Hajebi A, Saberi-Zafarghandi MB, Vares-Vazirian M, Asadi A. Demographic risk factors of suicide in Savojbolagh City of Tehran Province: 2007-2009. Ethno Med. 2013;7(3):143-8.

[6] De Leo D, Padoani W, Scocco P, Lie D, Bille-Brahe U, Arensman E, et al. Attempted and completed suicide in older subjects: results from the WHO/EURO Multicentre Study of Suicidal Behaviour. International journal of geriatric psychiatry. 2001;16(3):300-10.

[7] Jessen G, Andersen K, Arensman E, Bille-brahe U, Crepet P, Leo DD, et al. Temporal fluctuations and seasonality in attempted suicide in europe: Findings from the who/euro multicentre study on parasuicide. Archives of Suicide Research. 1999 1999/01/01;5(1):57-69.

[8] Ajdacic-Gross V, Weiss MG, Ring M, Hepp U, Bopp M, Gutzwiller F, et al. Methods of suicide: international suicide patterns derived from the WHO mortality database. Bulletin of the World Health Organization. 2008;86(9):726-32. 
[9] Värnik A, Kolves K, van der Feltz-Cornelis CM, Marusic A, Oskarsson H, Palmer A, et al. Suicide methods in Europe: a gender-specific analysis of countries participating in the "European Alliance Against Depression". Journal of Epidemiology and Community Health. 2008;62(6):54551.

[10] Värnik A, Kõlves K, Allik J, Arensman E, Aromaa E, Van Audenhove C, et al. Gender issues in suicide rates, trends and methods among youths aged 15-24 in 15 European countries. Journal of affective disorders. 2009;113(3):216-26.

[11] Vijayakumar L. Suicide prevention: the urgent need in developing countries. World psychiatry. 2004;3(3):158-9.

[12] Sullivan E, Annest JL, Luo F, Simon T, Dahlberg L. Suicide among adults aged 35-64 yearsUnited States, 1999-2010. Center for Disease Control and Prevention, Morbidity and Mortality Weekly Report. 2013.

[13] ASTARAKI P, KEIKHAVANDI S, MANSOURIAN M, BASHIRI S, QORBANI M, REZAPOOR A, et al. A Comparative Study of the Causes and Methods of Suicide Lead to Death Referred to Ilam Legal Medicine Center in 2004-2009. 2014.

[14] Amiri B, Pourreza A, Rahimi Foroushani A, Hosseini SM, Poorolajal J. Suicide and associated risk factors in Hamadan Province, West of Iran, in 2008 and 2009. Journal of research in health sciences. 2012;12(2):88-92.

[15] Pompili M, Innamorati M, Vichi M, Masocco M, Vanacore N, Lester D, et al. Inequalities and impact of socioeconomic-cultural factors in suicide rates across Italy. Crisis. 2011.

[16] Nazarzadeh M, Bidel Z, Ayubi E, Asadollahi K, Carson KV, Sayehmiri K. Determination of the social related factors of suicide in Iran: a systematic review and meta-analysis. BMC public health. 2013;13(1):1.

[17] Kim Y, Kim H, Kim D-S. Association between daily environmental temperature and suicide mortality in Korea (2001-2005). Psychiatry Research. 2011 4/30/;186(2-3):390-6.

[18] Woo J-M, Okusaga O, Postolache TT. Seasonality of suicidal behavior. International journal of environmental research and public health. 2012;9(2):531-47.

[19] Ajdacic-Gross V, Wang J, Bopp M, Eich D, Rössler W, Gutzwiller F. Are seasonalities in suicide dependent on suicide methods? A reappraisal. Social Science \& Medicine. 2003 10//;57(7):117381.

[20] Rock D, Greenberg DM, Hallmayer JF. Increasing seasonality of suicide in Australia 1970-1999. Psychiatry research. 2003;120(1):43-51.

[21] Sava NI, Papari AC. Comparative Study on the Phenomenon of Suicide Based on Gender and Season. Procedia - Social and Behavioral Sciences. 2015 2015/05/13;187:532-5.

*Corresponding author.

E-mail address: hosseini_hayam@yahoo.com 